\title{
СИСТЕМА ИНДИКАТОРОВ СОЦИАЛЬНО-ЭКОНОМИЧЕСКОГО РАЗВИТИЯ СЕЛЬСКИХ ДОМОХОЗЯЙСТВ ПСКОВСКОЙ ОБЛАСТИ
}

\section{AN INDEX SET SHOWING THE SOCIAL AND ECONOMIC DEVELOPMENT OF RURAL HOUSEHOLDS IN PSKOV OBLAST}

\section{E. Garskaya \\ A. Mamedov}

Summary. The article explicates a multi-sided research of the Pskov oblast rural population socio-economic situation nowadays. The research has revealed low indicators of the level of living as well as a poor demographic situation. The rural territory issues are evident and they pose a problem of Russia's loosing its territorial integrity owing to a decreasing numbers of rural population. One of the main reasons in this respect is the crisis of agriculture, the main source of the rural economy. Basing on the results of the research and deducing from them, a set of measures and actions to increase the Pskov oblast rural population level is offered.

Following more than fifteen year period of reforming the Russian economy including its agricultural and industrial complex, the poverty level of villagers has become much higher than one of people living in a city: $75 \%$ of villagers have money income per capita below the standard of living and $61 \%$ of villagers have disposable income per capita below the poverty level.

The research of the given problem is aimed at providing an opportunity for a comprehensive analysis of the processes in the social and labour sphere of settlements white their local conditions being taken into account. It results from the dramatic reduction of state reports and statements on the social and labour problems of settlements. The current status doesn't allow to analyse the processes taking place in the social and labour sphere of settlements in a comprehensive and authentic way. It makes impossible to find out differencies in the countryside.

Keywords: demography, demographic situation, statistics, level of living, poverty, mortality, agriculture.

\author{
Гарская Елена Сергеевна \\ К.э.н., ФГБОУ ВО «Великолукская государственная \\ сельскохозяйственная академия» \\ egarskaya@mail.ru \\ Мамедов Ахмед Курбанович \\ К.э.н., дочент, ФГБОУВО «Великолукская \\ государственная сельскохозяйственная академия» \\ supermak63@yandex.ru
}

Аннотация. Статья посвящена комплексному исследованию проблемы социально-экономического положения сельских домохозяйств Псковской области. В ходе исследования были выявлены низкие показатели уровня жизни населения, а также неблагоприятная демографическая ситуация. Проблемы сельской местности очевидны. Существует опасность сохранения территориальной целостности России, обусловленная постоянным уменьшением числа сельских жителей. Одной из главных причин такого положения дел является кризис базовой отрасли сельского хозяйства. Комплекс мероприятий и мероприятий, направленных на повышение уровня жизни сельского населения Псковской области, определяется аргументацией и результатами исследований.

После более чем пятнадцатилетнего реформирования экономики страны, в том числе ее агропромышленного комплекса, уровень бедности сельских жителей стал значительно выше, чем в городе: $75 \%$ сельских жителей имеют среднедушевой доход ниже прожиточного минимума, а $61 \%$ сельских семей имеют среднедушевые располагаемые ресурсы ниже черты бедности.

Результат исследования данной проблемы должен обеспечить возможность комплексного анализа процессов в социально-трудовой сфере села сучетом местных условий. Это связано с тем, что в последние годы резко сократилась государственная отчетность по социально-трудовым проблемам на селе. Такая ситуация не позволяет всесторонне и достоверно анализировать процессы, происходящие в социально-трудовой сфере села, отслеживать различия в условиях труда и жизни на селе.

Ключевые слова: сельское домохозяйство, демография, демографическая ситуация, статистика, уровень жизни, бедность, смертность, сельское хозяйство.

хозяйства и только в 8 районах области большую часть сельхозпродукции производили СХО (таблица 1). Для сравнения уровня развития территорий с преобладанием корпоративных и семейных хозяйств в производстве валовой продукции, мы сгруппировали и наглядно представили районы Псковской области в соответствующие группы по удельному весу сельскохозяйственных организаций в сельскохозяйственном производстве. Районы с удельным весом СХО в сельхозпроизводстве более 
Таблица 1. Группировка районов Псковской области по удельному весу сельскохозяйственных организаций в валовом производстве продукции сельского хозяйства в 2019 г. [6]

\begin{tabular}{|c|c|c|c|c|c|}
\hline \multirow{2}{*}{ Район } & \multirow{2}{*}{$\begin{array}{l}\text { Валовая продук- } \\
\text { ция сельского } \\
\text { хозяйства, млн. } \\
\text { руб. }\end{array}$} & \multirow{2}{*}{$\begin{array}{l}\text { Доля района в произ- } \\
\text { водстве с/х продукции, } \\
\text { в\% }\end{array}$} & \multicolumn{3}{|c|}{$\begin{array}{l}\text { Удельный вес в сельхоз производстве } \\
\text { района, в\% }\end{array}$} \\
\hline & & & CXO & $\mathbf{X H}$ & $K(\Phi) X$ \\
\hline Область всего & 9213625 & 100 & 51,2 & 46,4 & 2,4 \\
\hline ПСКОвский & 2147640 & 23,3 & 74,3 & 25,4 & 0,4 \\
\hline Новосокольнический & 565705 & 6,1 & 68,9 & 30,5 & 0,6 \\
\hline Порховский & 889867 & 9,7 & 65,1 & 30,6 & 4,3 \\
\hline Островский & 669828 & 7,3 & 62,7 & 35,4 & 1,9 \\
\hline Бежаницкий & 438512 & 4,8 & 57,5 & 42 & 0,5 \\
\hline Великолукский & 740183 & 8 & 55,9 & 43,3 & 0,8 \\
\hline Дедовичский & 297426 & 3,2 & 55,7 & 44 & 0,3 \\
\hline Дновский & 199909 & 2,2 & 51,7 & 47,7 & 0,6 \\
\hline Итого по 1 группе & 5949070 & 64,6 & 65,9 & 32,9 & 1,2 \\
\hline Палкинский & 248857 & 2,7 & 42,7 & 57,3 & 0 \\
\hline Себежский & 189150 & 2,1 & 41,7 & 58,2 & 0,1 \\
\hline Пыталовский & 201159 & 2,2 & 36,4 & 63 & 0,6 \\
\hline уньинский & 197805 & 2,1 & 35 & 65 & 0 \\
\hline Новоржевский & 260666 & 2,8 & 30,4 & 68,5 & 1,1 \\
\hline Гдовский & 187992 & 2 & 28,5 & 65,1 & 6,4 \\
\hline Опочецкий & 226454 & 2,5 & 26 & 73,9 & 0 \\
\hline Пустошкинский & 144175 & 1,6 & 25,9 & 71,6 & 2,5 \\
\hline Усвятский & 101479 & 1,1 & 21,8 & 71,4 & 6,8 \\
\hline Красногородский & 198070 & 2,1 & 21,3 & 74,3 & 4,3 \\
\hline Пушкиногорский & 203022 & 2,2 & 20,9 & 77,5 & 1,6 \\
\hline Локнянский & 195590 & 2,1 & 20,5 & 77,2 & 2,4 \\
\hline Струго-Красненский & 125610 & 1,4 & 17,6 & 82,2 & 0,2 \\
\hline Невельский & 260826 & 2,8 & 14,1 & 78,2 & 7,7 \\
\hline Плюсский & 104990 & 1,1 & 13,7 & 85 & 1,2 \\
\hline Печорский & 418710 & 4,5 & 6 & 74,9 & 19,1 \\
\hline Итого по 2 группе & 3264555 & 35,4 & 24,6 & 71 & 4,4 \\
\hline
\end{tabular}

50\% были объединены в 1-ю группу (группа с преобладанием корпоративного сектора в агропроизводстве), остальные вошли во 2-ую - группа с преобладанием семейного сектора (таблица 1).

Таблица 1 свидетельствует о том, что, во-первых, в первую группу хозяйств входили в 2019 г. всего лишь 8 районов (валовая продукция сельского хозяйства в СХО колебалась от 51,7\% в Дновском районе до 74,3\% в Псковском районе), которые превышали 2-ую почти на 50\%. Преобладающая часть районов области, а их 18, вошли во вторую группу районов.

Во-вторых, если усредненный показатель по Псковской области между СХO и малыми формами (XH, КФХ) сбалансирован: 51,2\% - СХО и 48,8\% - ХН, КФХ, то по группам эта разница увеличивается, особенно по второй группе, что свидетельствует о небольшой доле в производстве сельскохозяйственной продукции
СХО в этих районах, незначительными инвестициями и государственными субсидиями, вложенными в СХО, это в свою очередь порождает высокий удельный вес малых форм хозяйствования (ХН, КФХ) от $57 \%$ до $82 \%$, что, прежде всего, свидетельствует о высокой степени выживаемости второй группы хозяйств, в 16 из 24 районов Псковской области.

Что касается КФХ, то здесь мы видим ярко выраженный разброс по группам и районам, где статистические данные касательного этого уклада разновелики, и только в одном из 24 районов должное внимание уделено этому показателю, где доля КФХ достигла 19\% - это Печорский район, а если проанализировать детально этот уклад, то от 0-3\% - 18 районов, 4-8\% - 5 районов и 9-20\% - 1 район, это говорит о том, что значительная часть КФХ, а это 23 района, средние показатели не выходят за рамки $8 \%$ в общем удельном весе производства сельскохозяйственной продукции, хотя по средним ве- 


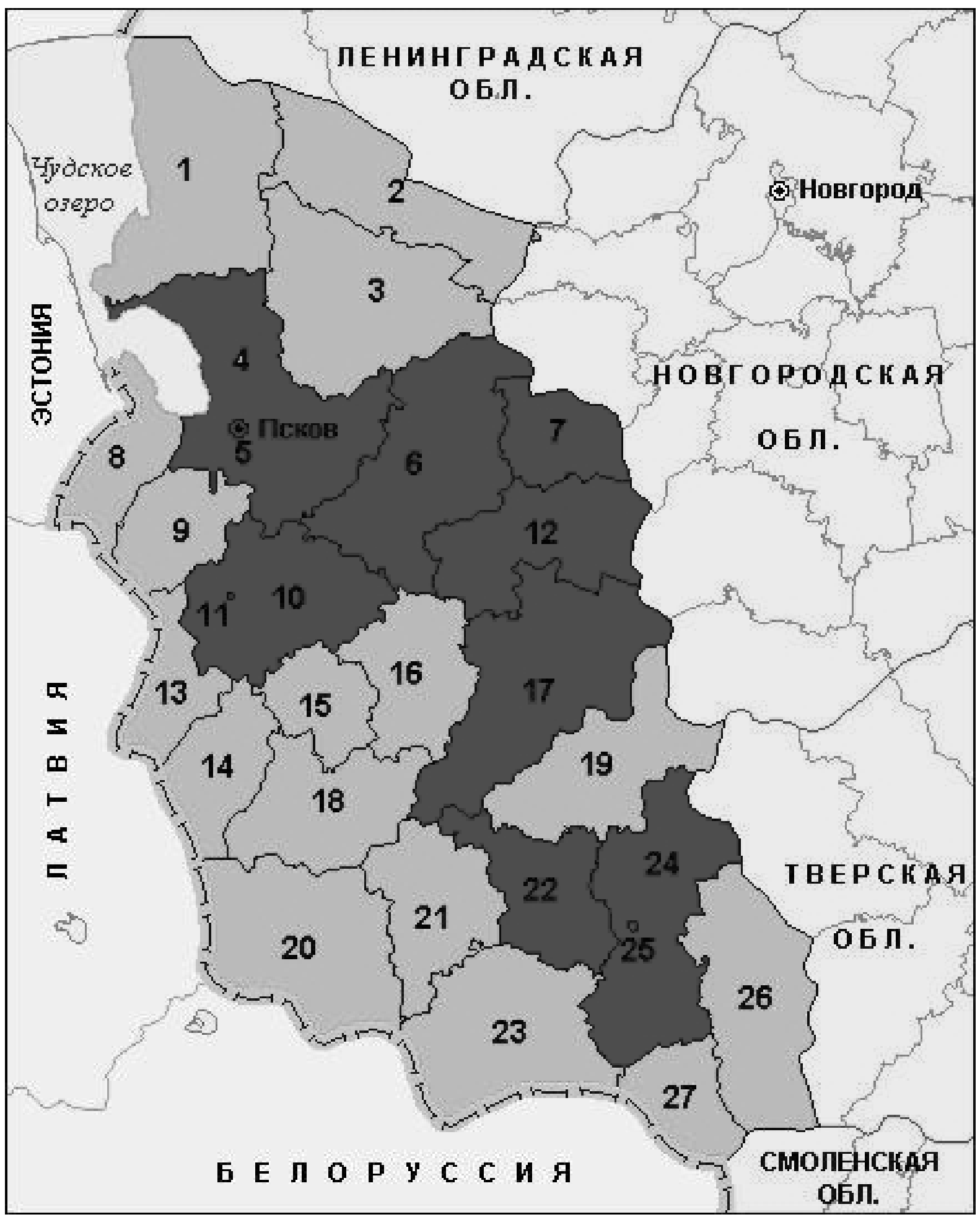

(условные обозначения: 1.Гдовский район, 2. Плюсский, 3. Струго-Красненский, 4. Псковский, 5. г. Псков, 6. Порховский, 7. Дновский, 8. Печорский, 9. Палкинский, 10. Островский, 11. г. Остров, 12. Дедовичский,

13. Пыталовский, 14. Красногородский, 15. Пушкино-Горский, 16. Новоржевский, 17. Бежаницкий,

18. Опочецкий, 19. Локнянский, 20. Себежский, 21. Пустошкинский, 22. Новосокольнический, 23. Невельский, 24. Великолукский, 25. г. Великие Луки, 26. Куньинский, 27. Усвятский)

- группа районов с развитым корпоративным сектором

— _ _ группа районов с развитым семейным сектором

Рис. 1. Группировка районов Псковской области (2019 г.) 
Таблица 2. Показатели качества жизни членов сельских домохозяйств районов Псковской области

\begin{tabular}{|c|c|c|c|c|c|c|c|}
\hline \multirow{2}{*}{ Районы Псковской области } & \multicolumn{7}{|c|}{ Показатели,\% } \\
\hline & 1 & 2 & 3 & 4 & 5 & 6 & 7 \\
\hline Великолукский & 2,1 & 3,9 & 1,6 & 4,3 & 4,1 & 49,8 & 10,1 \\
\hline Куньинский & 5,7 & 4,3 & 1,8 & 12,0 & 11,6 & 44,4 & 20,4 \\
\hline Гдовский & 2,0 & 3,2 & 2,5 & 5,4 & 2,3 & 56,4 & 12,7 \\
\hline Печорский & 3,2 & 8,5 & 1,6 & 10,2 & 9,8 & 38,3 & 19,9 \\
\hline Опочецкий & 8,6 & 9,1 & 2,5 & 18,1 & 17,7 & 38,6 & 23,6 \\
\hline Среднее значение & 4,3 & 5,8 & 2,0 & 10,0 & 9,1 & 45,5 & 17,3 \\
\hline
\end{tabular}

\section{Система показателей социально-экономического развития, включающая субъективную оценку респондента}

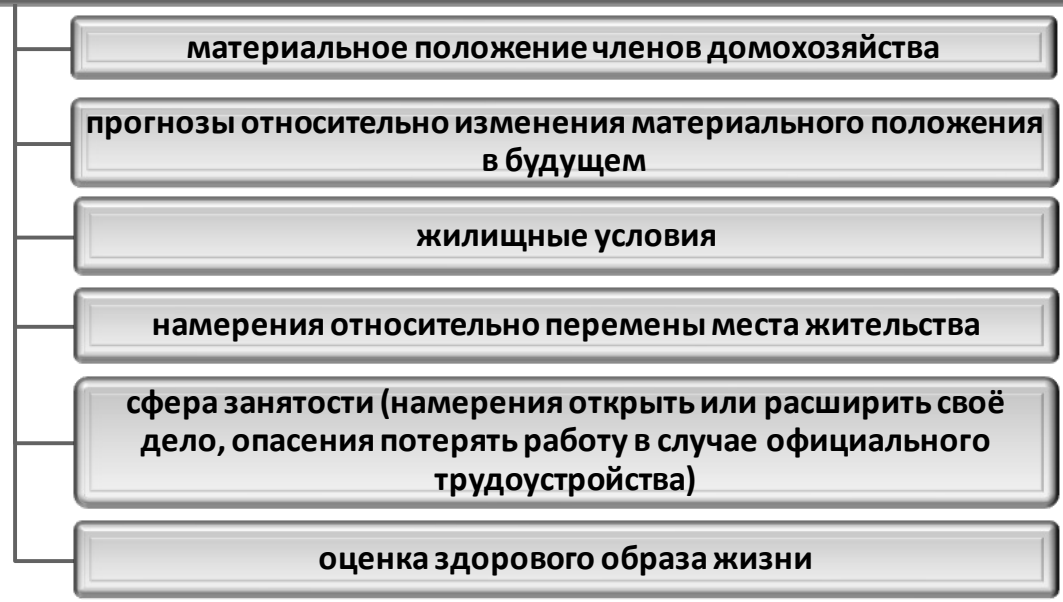

Рис. 2. Система показателей

личинам в удельном весе КФХ в сельскохозяйственном производстве в первой группе - 1,2\%, а во второй группе - 4,4\%, разница в 3,7 раза, что немного искажает реальные показатели.

В период с 2017 по 2020 годы проводился ряд социологических исследований, оценивающих уровень благосостояния жителей сельских территорий Псковской области. На основании сравнительного анализа результатов исследований был сделан вывод о степени информативности некоторого комплекса показателей для измерения уровня жизни сельского населения и, как следствие, социально-экономического развития сельских территорий в целом.

Степень информативности показателей подтверждается корреляцией ответов респондентов с официальными данными по динамике демографических и других статистических показателей последних лет, предоставляемых Росстатом Псковской области. При этом одним из преимуществ предлагаемой системы показателей является возможность учёта субъективных точек уровня и качества жизни сельских домохозяйств, зачастую выпадающих из обзора официальной статистики по причине невозможности фиксации всех аспектов в полном объёме.

Субъективные моменты уровня и качества жизни относятся к тем оценкам восприятия, которые присутствуют, в основном, в различных опросах общественного мнения или социальных обзорах. Они могут использоваться для дополнения объективных показателей, которые, тем не менее, также являются относительными, поскольку материальное положение респондента определяется не абсолютной суммой его дохода, а относительным положением по шкале доходов, общественным статусом. В итоге респондент может как выиграть от роста абсолютного уровня своего дохода, так и считать свое положение не изменившимся по шкале доходов-расходов.

В итоге можно отметить, что поскольку качество жизни является многогранным понятием, его практически 
Таблица 3. Индикаторы качества жизни в регионе,\%

\begin{tabular}{|l|l|l|l|l|}
\multirow{2}{*}{$№$} & $\mathbf{2 0 2 0}$ год & Отклонение \\
\cline { 3 - 5 } & Позикатор & 22,7 & 77,3 & $-54,6$ \\
\hline 1. & Благосостояние населения & 82,4 & 17,6 & 64,8 \\
\hline 2. & $\begin{array}{l}\text { Оценка улучшения благосостояния } \\
\text { населения }\end{array}$ & 72,0 & 28,0 & 44,0 \\
\hline 3. & Жилищные условия & 89,6 & 10,4 & 79,2 \\
\hline 4. & Возможность миграции & 44,6 & 55,4 & $-10,8$ \\
\hline 5. & $\begin{array}{l}\text { Перспективы открытия своего дела } \\
\text { (бизнеса) }\end{array}$ & 41,3 & 58,7 & $-17,4$ \\
\hline 6. & Опасения потерять работу & 82,7 & 17,3 & 65,4 \\
\hline 7. & Здоровый образ жизни & & \\
\hline
\end{tabular}

невозможно измерить единым показателем, и ни субъективные, ни объективные оценки, рассматриваемые в отдельности, не являются решающими измерителями качества жизни. Поэтому следует применять их в комплексе.

Ряд показателей, используемых в процессе проведения социологических опросов, не вошли в итоговый перечень показателей и не могут быть рекомендованы для включения в систему по причине низкой информативности при рассмотрении их как отдельно, так и в системе с другими показателями.

В итоге результатом проведённого исследования выступила система показателей, включающая субъективную оценку, представленная на рисунке 2:

В таблице 2 представлено количественное выражение указанных показателей по исследуемым районам Псковской области:

- материального положения членов домохозяйства (1);

- прогнозов относительно изменения материального положения в будущем (2);

- жилищных условий (3);

- намерений относительно перемены места жительства (4);

- сферы занятости (намерения открыть или расширить своё дело (5);

- опасения потерять работу (6);

- здорового образа жизни (7).

В случае наличия внутри показателя дифференциации на систему подвопросов указывались значения, выступающие как взаимодополняющие по отношению друг к другу и позволяющие отразить наиболее проблемные моменты социально-экономической сферы региона.

В таблице 3 представлены индикаторы качества жизни в регионе (Псковской области). В случае отрицатель- ного отклонения показателя негативная субъективная оценка той или иной сферы жизни населения преобладает над положительной, что демонстрирует наличие определенной проблемы, и требует принятия мер. Следует отметить, что чем больше положительное отклонение, тем благоприятнее социально-экономическая ситуация.

Данная система показателей включает экономические, физические и психологические индикаторы.

Анализ материального положения членов домохозяйств говорит о том, что в период с 2017 по 2020 год резко сократился процент домохозяйств, члены которых испытывают трудности в обеспечении семьи минимальным набором материальных благ. Это подтверждает данные статистики, согласно которым численность населения с денежными доходами ниже величины прожиточного минимума сокращается относительно показателей 2016-2017 годов.

Вместе с тем с помощью данного субъективно оцениваемого показателя представляется возможным сформулировать развёрнутые суждения относительно дифференциации домохозяйств по уровню реальных доходов, а также судить о степени готовности населения позитивно оценивать минимальную потребительскую корзину и в целом о степени лояльности восприятия населением экономической ситуации в регионе.

Прогнозы относительно изменения материального положения в будущем. В регистрируемый период зафиксирован устойчивый рост ответов с позитивной коннотацией. На основании сопоставления полученных нами данных с данными ВЦИОМ периода январь-март 2020 г. выдвинута гипотеза о том, что данный показатель позволяет в первом приближении оценить уровень доверия электората власти.

По показателю «оценка жилищных условий» отмечается устойчивая корреляция между данным показа- 
телем и данными официальной статистики по разделу «Общая площадь жилых помещений». Из этого следует вывод о взаимозаменяемости данных показателей при проведении ситуативных обследований.

При этом следует отметить, что на фоне увеличения общей площади жилых помещений в домохозяйствах увеличивается процент семей, планирующих улучшить свои жилищные условия в будущем. Данная тенденция более чётко фиксируется значением показателя «намерения относительно перемены места жительства», согласно которому процент желающих сменить место жительства с сельских населённых пунктов на городские за период с 2017 по 2020 год снизился более чем на 10\%.

При регулярном отслеживании данных показателей возможно своевременное прогнозирование миграционных потоков. Принятие мер для поддержания положительной динамики показателей позволит рассматривать Псковскую область не только в качестве миграционного донора для соседних регионов, но и повысить её значимость как субъекта сельскохозяйственной деятельности.

Проведённое нами исследование показало, что развёрнутый анализ причин возникновения намерения перемены места жительства позволяет выявить факторы, воспринимаемые населением как наиболее неблагоприятные, зачастую несовместимые с физическим проживанием на определённой территории. Это даёт более ясную картину восприятия обеспеченности населённых пунктов её объектами по сравнению с исследованиями, в которых вопросы относительно социальной инфраструктуры задавались респондентам напрямую. В последнем случае ответы респондентов демонстрировали устойчиво завышенную негативную оценку состояния инфраструктуры.

Таким образом, показатели «оценка жилищных условий» и «намерения относительно перемены места жительства» позволяют сформировать более ясную картину и выявить наиболее проблемные места социальной инфраструктуры сельской территорий.

Показатель субъективной оценки сферы занятости был раскрыт в ходе проведения исследования в двух аспектах: как намерение открыть или расширить своё дело и как опасение потерять работу в случае официального трудоустройства респондента. По первому аспекту была замечена позитивная динамика в намерениях расширения хозяйства, но по-прежнему фиксируются опасения открывать собственное дело.

По второму аспекту прослеживается тенденция на увеличение опасений респондентов потерять работу. Данные опасения коррелируют с достаточно резким сокращением зарегистрированных в органах государственной службы занятости количества безработных в Псковской области в 2017 году.

В 2019 году впервые в анкету был введен вопрос для оценки образа жизни (здоровый, не совсем здоровый, нездоровый). Несмотря на то, что нет возможности отслеживать динамику индикатора, его использование в презентации целесообразно. Он сочетает в себе ряд значительных разрозненных показателей, таких как количество поликлиник, количество врачей и фельдшеров, заболеваемость и сокращение продолжительности жизни в результате вредных привычек и т.д. Таким образом, этот показатель является интегральным.

В ходе исследования было выявлено, что изучение субъективной оценки качества жизни населения позволяет говорить о преобладании положительных оценок. Данные опроса также подтвердили наличие положительных изменений в качестве жизни населения за последние несколько лет.

Таким образом, происходит улучшение материального положения населения, что выражается в увеличении реальных денежных доходов; сокращение количества бедных; повышение уровня занятости населения при постоянном снижении уровня безработицы и др. В социальной сфере можно отметить увеличение площади жилья на одного жителя в среднем, положительную тенденцию улучшения жилого фонда и придомовых территорий.

Однако наряду с положительными изменениями качества жизни населения Псковской области отмечается также ряд негативных факторов. В региональной экономике остаются проблемы доступности жилья для отдельных категорий граждан. В сфере здравоохранения наблюдается недовольство граждан качеством медицинской помощи.

Результаты исследования также позволяют сделать вывод, что для выявления динамики изменения качества жизни владельцев сельских домохозяйств в Псковской области необходимо регулярно проводить мониторинг основных показателей качества жизни, что повысит эффективность выбора механизмов его обеспечения и совершенствования. Социологический анализ качества жизни населения может стать одним из эффективных инструментов такого мониторинга. Он позволяет выявить комплекс объективных и субъективных показателей, характеризующих изменение жизненных сил населения, его жизненного пространства, а также оценить механизмы обеспечения качества жизни с точки зрения их эффективности.

Таким образом, система показателей социально-экономического развития сельских территорий регио- 
на представляется оправданной. Предлагаемая система показателей позволяет формировать комплексную оценку не только уровня и качества жизни населения, но и динамики социально-экономического развития региона в целом, а также прогнозировать миграционные тенденции. Выявленная корреляция официальных данных с результатами социологического исследования позволяет предложить использование социологических методов как экспресс-оценки существующих тенденций.

Комплексный анализ уровня жизни собственников сельских домохозяйств в исследуемом регионе (Псков- ская область) показал, что уровень заработной платы в аграрном секторе остается низким. Основным источником дохода для большинства сельских жителей является продажа продукции, произведенной в их личном подсобном хозяйстве. Доля заработной платы в структуре денежных доходов сельского населения существенно снизилась (до 30\%) за счет увеличения доли прочих доходов. Потребление наиболее питательных продуктов питания на душу населения в сельской местности ниже, чем на душу населения в городских районах, что указывает на более низкое качество жизни. Проблема социального развития села продолжает оставаться актуальной проблемой.

\section{ЛИТЕРАТУРА}

1. Демографические показатели Псковской области. Статистический сборник. - Псковоблкомстат, 2016-2019.

2. Концепция стратегии социально-экономического развития Псковской области (краткая версия). - СПб.: ЦСР «Северо-Запад», 2009. - 21 с.

3. Предположительная численность населения Псковской области до 2030 года (Статистический бюллетень). Росстат. Псков. — 2009.

4. Территориальный орган Федеральной службы государственной статистики по Псковской области. URL: http://pskovstat.gks.ru/digital/region1/default.aspx.

5. Федеральная служба государственной статистики. Естественное движение населения Российской Федерации. URL: http://www.gks.ru/bgd/regl/b11_106/ Main.htm.

6. База данных муниципальных образований, URL: http://www.gks.ru

○ Гарская Елена Сергеевна ( egarskaya@mail.ru ), Мамедов Ахмед Курбанович ( supermak63@yandex.ru ).

Журнал «Современная наука: актуальные проблемы теории и практики»

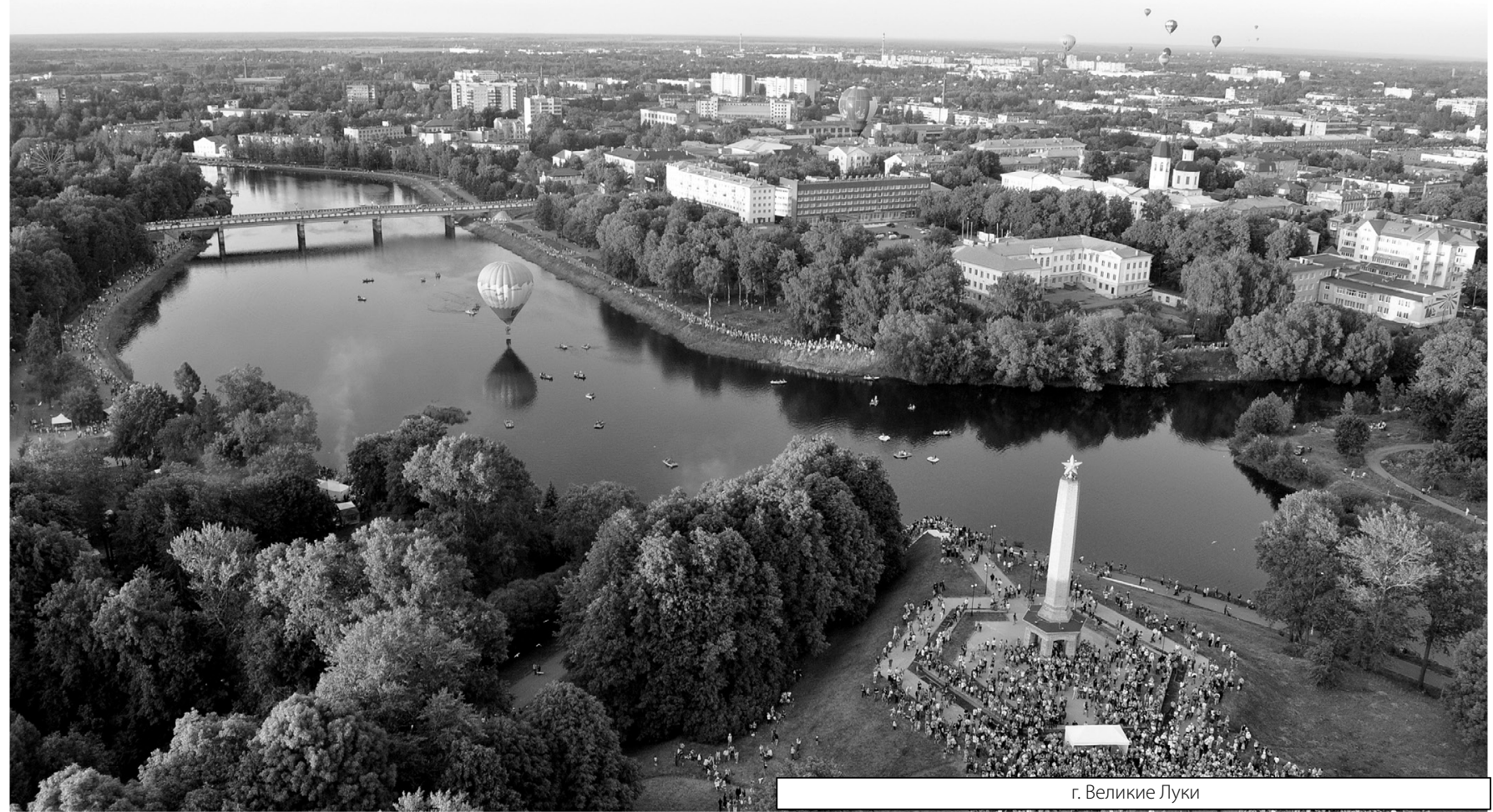

